\title{
Pentingnya Layanan Konseling Berbasis Kesehatan Mental di Lembaga Pemasyarakatan
}

\author{
Siti Warniyanti \\ Jurusan Bimbingan dan Kosneling, Universitas Negeri Padang, Sumatera Barat. \\ Indonesia
}

\begin{abstract}
Kebebasan dalam berpendapat mengenai, hak azasi manusia, kebebasan, kesehatan dan kesejahteraan baik fisik maupun secara psikologis sedang di galakkan untuk menjadi masyarakat revolusi industri milenial, menuju perubahanyang lebih baik. Setiap orang memiliki kesempatan dalam berkomentar atau memberikan dukungan dan sebagainya mengenai hak azasi manusia, kesejahteraan, kesehatan baik fisik maupun psikologis. Sedangkan warga binaan lembaga pemasyarakatan atau narapidana yang berada di dalam tahanan tidak memiliki itu semua. Dimana kehidupan sebagai narapidana di Lembaga Pemasyarakatan merupakan bentuk dari konsekuensi atau hukuman atas perilaku melanggar hukum yang telah dilakukan. Berbagai permasalahan dialami narapidana dalam menjalani kehidupan di Lembaga Pemasyarakatan, diantaranya perubahan hidup, hilangnya kebebasan dan hak-hak yang semakin terbatas, masalah psikologis, hingga memperoleh label panjahat yang melekat pada dirinya serta kehidupan di masyarakat. Terutama untuk kesehatan mental narapidana berkaitan dengan penerimaan diri dan persiapan diri untuk terjun kembali ke kehidupan masyarakat dengan menyandang status mantan narapidana
\end{abstract}

Keywords: Konseling, Narapidana, Kesehatan Mental

Article History: Received on 15/10/2017; Revised on 14/11/2017; Accepted on 21/11/2017; Published Online: 28/11/2017.

$\begin{aligned} & \text { This is an open access article distributed under the Creative Commons Attribution License, which permits unrestricted use, } \\ & \text { distribution, and reproduction in any medium, provided the original work is properly cited. C2017 by author. }\end{aligned}$
PENDAHULUAN

Hukum memang sangat baik jika ditegakkan dengan adil. Sehingga dapat terwujudnya kehidupan masyarakat yang madani. Bagi yang melanggar hukum dapat dikenakan hukuman sesuai dengan pelaggaran yang dilakukan. Bagi mereka yang tinggal di penjara atau menerima binaan di Lembaga Pemasyarakatan, untuk menjalani hukuman kurungan disebut narapidana.

\section{Narapidana}

Warga Binaan Pemasyarakatan adalah Narapidana, Anak Didik Pemasyarakatan, dan Klien Pemasyarakatan. Terpidana adalah seseorang yang dipidana berdasarkan putusan pengadilan yang telah memperoleh kekuatan hukum tetap. Narapidana adalah Terpidana yang menjalani pidana hilang kemerdekaan di LAPAS.(Indonesia, 1995). Menurut Atmasasmita, narapidana adalah individu pelaku tindak pidana yang telah diputus bersalah oleh majelis hakim dan dihukum penjara selama kurun waktu tertentu, kemudian ditempatkan dalam rumah tahanan sebagai tempat pelaksanaan hukuman tersebut. Rumah tahanan merupakan suatu institusi yang diberi kewenangan untuk 
memperbaiki perilaku pelanggar hokum. (Yulianti, Aat Sriati dan Restuning Widiasih, 2009).

Seseorang di sebut sebgai narapidana atau napi di karenakan melakukan suatu tindak kriminal. Menurut Stuart \& Sundeen tindak kriminal sebagai akibat dianggap sebagai solusi yangdapat digunakan untuk mengatasi masalahhidup. Tindakan ini sebagai akibat kurangkreatifnya masyarakat mencari solusi atasmasalah kehidupan yang dihadapi (Sarwono, 2005).Kurang kreatifnya masyarakat dalammenyikapi masalah kehidupan dapatdikategorikan mekanisme koping yangdestruktif karena masyarakat tidak dapatmengelola stressor dengan baik sehinggatindakan yang dilakukan tidakmenyelesaikan masalah, bahkanmenimbulkan masalah baru yang lebihserius (Megah Andriany, 2011).

Sedangkan warga binaan lembaga pemasyarakatan atau narapidana yang berada di dalam tahanan tidak memiliki itu semua. Dimana kehidupan sebagai narapidana di Lembaga Pemasyarakatan merupakan bentuk dari konsekuensi atau hukuman atas perilaku melanggar hukum yang telah dilakukan. Berbagai permasalahan dialami narapidana dalam menjalani kehidupan di Lembaga Pemasyarakatan, diantaranya perubahan hidup, hilangnya kebebasan dan hak-hak yang semakin terbatas, kekerasa di dalam penjara, masalah psikologis, hingga memperoleh label panjahat yang melekat pada dirinya serta kehidupan di masyarakat. Selama berada di Lembaga Pemasyarakatan membuat narapidana harus terpisah dari keluarga dan hidup bersama narapidana lain. Status sebagai narapidana bukan suatu hal yang dengan mudah dapat diterima oleh seseorang, namun secara tidak langsung narapidana dituntut untuk mempertanggungjawabkan tindak pidana yang ia lakukan serta kemudian mampu memiliki penerimaan diri, memiliki hubungan positif dengan orang lain, memiliki cara dalam penguasaan lingkungan, dan memiliki tujuan hidup. Terutama untuk kesehatan mental narapidana berkaitan dengan penerimaan diri dan persiapan diri untuk terjun kembali ke kehidupan masyarakat dengan menyandang status mantan narapidana.

Menurut Gusef (2011), menemukan bahwa mantan narapidana mengalami kesulitan untuk beradaptasi dan bersosialisasi kembali dengan masyarakat akibat adanya stigma negatif. Mantan narapidana berusaha menghilangkan stigma negatif agar mereka mampu berbaur, mendapatkan pekerjaan, dan juga mendapatkan kembali kehormatannnya di mata masyarakat. Mereka beradaptasi dengan cara yang berbedabeda sesuai dengan kasus dan juga tempat tinggal mereka. Purnomo (1986), mengatakan bahwa pemasukan pelanggar hukum ke dalam Lemaga Pemasyarakatan akan berpotensial menimbulkan bahaya-bahaya sekunder seperti prisonisasi dan stigmatisasi. Prisonisasi adalah proses belajar sosial yang mengakibatkan terkontaminasinya mental penghuni dengan nilai-nilai yang terdapat di penjara termasuk juga kemungkinan terjadinya degradasi atau penurunan derajat harga diri manusia. Stigmatisasi adalah pemberian label negatif dari masyarakat kepada pelanggar hukum tersebut.(Kepemudaan, 2013)

Sesuai denga pernyataan diatas, yang berkaitan erta dengan permasalahan diatas adalah kesehatan mental narapidana baik yang masih dalam masa tahanan ataupun yang akan kembali ke kehidupan masyarakat. Maka dari itu kesehatan mental narapidana perlu diperhartikan tidak hanya sarana dan prasarana yang ditingkatkan tetapi juga 
pelayanan yang disediakan untuk narapidana. Sehingga dalam perencanaan masa depan baru narapidana dapat lebih baik.

Seseorang yang menjadi narapidana adalah dia yang melakukan perbuatan yang dinyatakan terlarang oleh undang-undang di negara Indonesia dan ditentukan olehproses hukum harus ditempatkan di dalam Lembaga Pemasyarakan sehingga hilang kemerdekaannya. Hilangnya kemerdekaan pada mereka yang menjadi narapidana akan menimbulkan rasa penurunan martabat serta harga diri, sehingga stres muncul dan menurut Adhayani Lubis, jika seorang anak masuk dalam Lembaga Pemasyarakatan, dia akan menyadari bahwa dirinya akan dalam keadaan terkekang, jauh dari orang tua, keluarga dan orang-orang yang dikenalnya, serta akan memasuki dunia yang tertutup, sehingga cenderung untuk mengalami depresi. Selain itu, lamanya vonis hukuman dan frekuensi mereka dikunjungi keluarga dan teman juga akan memengaruhi meningkatnya gejala depresi (Karnovinanda Rhapsody, 2014).

"Prisons are bad for mental health: There are factors in many prisons that have negative effects on mental health, including: overcrowding, various forms of violence, enforced solitude or conversely, lack of privacy, lack of meaningful activity, isolation from social networks, insecurity about future prospects (work, relationships, etc), and inadequate health services, especially mental health services, in prisons. The increased risk of suicide in prisons (often related to depression) is, unfortunately, one common manifestation of the cumulative effects of these factors"(World Health Organization, 2005)

Sedangkan dalam WHO, mengemukakan bahwa penjara atau lapas buruk bagi kesehatan mental, karena beberapa faktor yang memiliki efek negatif, seperti kehilangan kebebasa, kehilangan privasi, tidak terhubung dengan sosial media, dll. Secara umum dampak psikologis bagi warga binaan dalam menjalani sanksi pidananya dapat berupa derita atau kesakitan, menurut Meilina antara lain : Loost of personality, seseorang warga binaan selama dipidana akan kehilangan kepribadian diri, identitas diri, akibat peraturan dan tatacara hidup di lembaga pemasyarakatan. Loost of security, selama menjalani pidana warga binaan selalu dalam pengawasan petugas sehingga warga binaan merasa selalu dicurigai dan merasa selalu tidak dapat berbuat sesuatu atau bertindak karena takut kalau tindakanya merupakam suatu kesalahan yang dapat berakibat dihukum atau dapat sanksi. Loost of liberty, hilangnya kemerdekaan individual, misalnya kemerdekaan berpendapat, kemerdekaan membaca surat kabar secara bebas, melakukan hobby. Loost of personal communication, kebebasan berkomunikasi tehadap siapapun juga dibatasi.

Loost of heterosexual, selama menjadi pidana, warga binaan ditempatkan dalam blok-blok sesuai dengan jenis kelaminnya. Penempatan ini menyebabkan warga binaan juga merasakan betapa naluri seks, kasih sayang, rasa aman bersama keluarga terampas,yang akan menyebabkan adanya penyimpangan seksual. Loost of prestige, warga binaan juga telah kehilangan harga diri.Loost of belief, akibat dari berbagai perampasan kemerdekaan, sebagai dampak dari pidana penjara, warga binaan menjadi kehilangan akan rasa percaya dirinya yang disebabkan olehketidaknyamanan dalam penjara, tidak dapat membuat keputusan, kurang mantap dalam bertindak. Loost of creativity, selama menjalani pidana, warga binaan jugaterampas kreatifitasnya, ide-idenya, gagasanya, imajinasinya, bahkan juga impian dan cita-citanya (Hayati, 2015) 
Berdasarkan beberapa pendapat di atas, dapat diketahui banyak permasalahan narapidana, seperti kehilangan identitas diri, hkehilangan hak kebebasan, kehilangan kebebasan komunikasi, serta mendapat stigma negatif dari masyarakat hingga terganggunya kesehatan psikologis karena kehilangan hak-hak lainnya. Sedangkan selama menjalani masa tahanan dan setelah menjalani masa tahanan, diharapkan narapidana memiliki kesehatan baik fisik maupun secara psikologisnya. Serta diharapkan narapidana memiliki perenacnaan masa depan yang baik, setelah keluar dari penjara.

Sesuai yang diharapkan baik oleh pihak pemerintah, dan narapidana itu sendiri bahwa, perlakuan (hukuman) terhadap narapidana bersifat mendidik dan membina narapidana agar menjadi manusia yang lebih baik, penuh percaya diri, berguna bagi bangsa dan negara serta bertakwa terhadap Tuhan Yang Maha Esa dan menjunjung tinggi norma dan nilai yang berlaku dalam masyarakat. Proses pemasyarakatan bertujuan untuk membina dan mendidik narapidana agar sadar akan tindakan kejahatan yang sudah mereka lakukan dan tidak mengulanginya kembali. Setelah meneriima hukuman dan mendapatkan pembinaan, narapiadana daat kembali merasakan udara segar di luar dinding Lapas. Kebebasan merupakan proses yang paling ditunggu oleh narapidana yangsedang menjalani masa hukuman. Narapidana yang akan dikembalikan ke lingkungan masyarakat dan berkumpul dengan keluarga dan saudara serta dapat kembali berinteraksi dengan masyarakat. Dengan beban mental yang dialaminya maka narapidana sulit untuk bersosialisasi dengan lingkungan masyarakat disekitarnya dengan perdikat beban mental sebagai narapidana menjadi tantangan yang amat berat di jalani narapidana itu sendiri.(Psikis, Polisi, \& Padang, 2012).

\section{Kesehatan Mental}

Kesehatan mental bagi narapidana perlu diperhatikan dengan adanya pelayanan memadai yang diberikan oleh pihak Lemba Pemasyarakatan (Lapas). Kesehatan mental adalah terhindarnya orang dari gejala-gejala gangguan jiwa (neurose) dan dari gejalagejala penyakit jiwa (psychose), dan mampu menyesuaikan diri dengan diri sendiri, dengan orang lain dan masyarakat serta lingkungan di mana ia hidup sehingga dapat mengembangkan dan memanfaatkan segala potensi, bakat dan pembawaan yang ada semaksimal mungkin, sehingga membawa kepada kebahagiaan diri dan orang lain dan keharmonisan yang sungguh-sungguh antara fungsi-fungsi jiwa.(Hasan Ramli dan Wiwik Utami, 2012).Profil kesehatan mental narapidana berdasarkan hasil penelitian Riri Sepnita Jashani, Ahmad Zaini, Joni Adison, sebagai beriku: 1) Profil Kesehatan Mental Narapidana dilihat Perasaan Sosial, Informasi yang diperoleh dari informan kunci yaitu merasa bersalah akan perbuatannya, dan merasa canggung dan sedih saat pertama didalam sel pada saat itu timbulnya penyesalan pada diri atas kesalahan yang dilakukannya, pada saat pertama di dalam sel merasakan kegelisahan dalam dirinya karna baru pertama masuk penjara. 2) Profil Kesehatan Mental Narapidana dilihat Perasaan Sosial, Informasi yang diperoleh bahwa emosi psikis narapidana dilihat dari perasan asusilanya adalah, dimana merasa bersalah dengan melanggar hukum dan menyesali perbuatannya, berjanji akan menjalani hukuman maupun peraturan yang ada selama di dalam sel, dan berprilaku yang baik selama didalam sel. (Psikis et al., 2012) 
Seorang individu yang merasa berdosa dan penuh dengan kemaksiatan akan menghalangi dirinya memperoleh kebahagiaan. Karena itu, seorang individu yang berada dalam dosa harus segera sadar dan bertobat. Perasaan berdosa dan bersalah adalah mudharat yang teramat merugikan bagi terwujudnya kesehatan mental. Secara umum pendekatan takhalliyah al-nafs, tahalliyah al-nafs dan tajalliyah al-nafs dalam sufisme berfungsi sebagai proses untuk preventive, curative dan constructive atas masalah gangguan psikologis dan dapat pula memperkembangkan kesehatan mental dan kepribadian. (Ag, 2015)

\section{Layanan Konseling}

Layanan yang dilakukan untuk membina narapidana di Lapas menurut Vina, layanan yang dapat diberikan di Lapas untuk narapidana yaitu konseling, pendidikan mental spiritual (agama), pendidikan formal, dan ketrampilan diberikan negara kepada para narapidana. Bahkan di Pekanbaru, napi atau yang sering disebut warga binaan LP tidak saja mendapatkan keterampilan, namun juga mendapatkan kesempatan untuk kuliah sambil menjalani hukuman.(Sosial, n.d.)

Layanan yang diberikan di Lapas, dapat diberikan dengan berbagai cara dengan agar Narapidana sebagai klien merasa terbuka untuk mengunkapkan masalahnya, pola komunikasi yang baik mendukung terjasinya hal tersebut. Menurut Wibawa, dkk, pola komunikasi dan pembinaan dalam rehabilitasi pengguna narkotika di lapas Klas II Yogyakarta terdiri dari dua pola. Pertama, pola komunikasi informal dan pola komunikasi formal. Pola komunikasi informal berlangsung dalam situasi yang akrab, terbuka dan saling menghargai. Pola komunikasi yang dikembangkan seperti ini sangat efektif menjaga kepercayaan warga binaan dengan petugas sehingga terbentuk suasana yang kondusif. Pola komunikasi yang sifatnya informal juga dilakukan dalam bentuk ceramah-ceramah keagamaan yang terjadwal, bimbingan konseling dengan konselor dari luar Lapas yang hadir seminggu sekali dan kegiatan-kegiatan di luar kamar lainnya. (Wibawa, Utami, \& Fatonah, 2014).

Layanan konseling sangatlah di perlukan untuk membantu narapidana dalam meningkatkan kesehatan mental, penerimaan siri dan kesiapan diri untuk kembali ke kehidupan masyarakat. Di Brunei Darussalam, pelayanan konseling bagi narapidana telah dilakukan dengan menggunakan dua tipe konseling yaitu dengan layanan konseling individual dengan layanan konseling kelompok. Dimana konseling kelompok lebih efektif dengan berbagai topik yang lebih spesifik dan masalah untuk dibahas dalam konseling kelompok.

"Two types of counseling occur in Brunei prisons-individual and group. Individual or Personal counseling is to assist the clients in resolving personal issues that may be preventing them from achieving their potential and everything discussed with a counselor is strictly confidential. On the other hand, group counseling involves a small number of people (usually 610) who meet together, along with one or two counselors to talk about their struggles and problems. These groups can take a variety of forms. Some focus on a specific topic or problem, while others address a number of different concerns. Of the two modes of counseling, group counseling is thought to be more effective than individual counseling" (Yusuf \& Mundia, 2014). 
Sedangkan menurut Asosiasi Art Therapy Amerika, dimana Art Therapy digunakan dalam memberikan layanan konseling kesehatan mental memiliki lebih banyak manfaat dalam mengkoreksi letak masalah yang dialami oleh narapidana. "the therapeutic use of art making, within a professional relationship, by people who experience illness, trauma, or challenges in living" (Gussak, 2007). Layanan konseling berbasis kesehatan mental telah di laksanakan, di Kumasi, Ghana, dimana konseling juga dilakukan dengan menggunakan layanan konseling individual dan kelompok. Selain itu juga dinyatakan bahwa konseling itu salah satu aspek penting dalam hidup.

"Kumasi Central Prison has a structure to offer personal and group Guidance and Counselling to inmates. The counselling section has a counselling structure to offer educational, vocational and personal or psychological counselling to the inmates. These services are to be offered in either personal or in group forms. Guidance and Counselling is an important aspect of life. This is the case because the aim is to assist individuals appreciate their situation and make choices offered by counsellors so that they can effect a positive change that will eventually affect their immediate community and the society at large"(Aba Afari, Osei, \& Adu-Agyem, 2015)

Sedangkan di Inggris, pelayanan kesehatan mental dan well-being sudah diterapkan dan ditingkatkan sejak tahun 2017. Pemertintah Inggris juga mendukung adanya pelayanan departemen kesehata dan bimbingan kesehan.

"Health and well-being services in prison should seek to improve health and well-being (including parity of esteem between services that address mental and physical health), tackle health inequalities and wider determinants of health and contribute to protecting the public and reducing reoffending."(Service \& England, 2019)

Begitu juga dengan penelitian yang dilakukan Evi, dkk yang menjelaskan bahwa dengan menggunakan layanan konseling individual untuk mengentaskan maslah di Lapas tersebut denga hasil, terdapat perbedaan kesehatan mental warga binaan wanita kasus non-narkoba di Lapas anak Pekanbaru sebelum dan sesudah dilaksanakan layanan konseling individual. Hal ini menunjukkan bahwa konseling individual dapat meningkatkan kesehatan mental warga binaan wanita kasus non-narkoba di Lapas anak Pekanbaru. Juga terdapat pengaruh konseling individual terhadap kesehatan mental warga binaan wanita kasus non-narkoba di Lapas anak Pekanbaru ditinjau dari setiap aspek-aspek kesehatan mental. (Program, n.d.)

Menurut Morrissey dan Cuddeback, pemberian layanan haruslah fokus pada kebutuhan, krisis stabilitas, bukan pada lamanya pemberian layanan. "services should focus on assessment, crisis stabilization, and diversion-not on long-term treatment," (Daifotis, 2018). Serta dalam memberikan pelayanan sebaiknya konselor dapat menerima klien apa adanya, dengan segala yang keunikan yang dimiliki klien. Hal ini sesuai dengan pendapat berikut:

"Given this heterogeneity of prison populations, it is no surprise that offenders present with unique problems and challenges that necessitate specialized skills and knowledge (e.g., impact of systemic punishments on mental illnesses, crisis management for segregated inmates lacking social support, facilitation of treatment gains in a punitive correctional environment)". (Morgan, Rozycki, \& Wilson, 2004).

Sehingga dalam pemberian layanan kepada narapidana hendaklah mengenai sasaran atau akar masalah sehingga narapidana dapat mengentaskan masalah yang ia alami dengan tepat. Seginer (Batang, Akbar, \& Primatexco, 2013) menyampaikan tiga 
komponen orientasi masa depan, yaitu: motivasional, representasi kognitif, behavioral. Motivasional (motivational). Hubungan antara orientasi masa depan dan motivasi pencapaian menarik para peneliti untuk mendeskripsikan aspek motivasi dari orientasi masa depan menjadi tiga konsep, yaitu: value, expectancy, control.Representasi kognitif (cognitive representation) Sepanjang penelitian yang dilakukan peneliti tertarik pada aspek kognitif dari orientasi masa depan. Kognitif dideskripsikan ke dalam dua dimensi; content dan valence. Content berisi mengenai variasi kehidupan yang digambarkan individu di masa depan. Sedangkan valence didasarkan pada asumsi dimana individu dihubungkan dengan masa depan yang berhubungan dengan apa yang akan diraih dan apa yang ingin dihindari, dan ini di ekspresikan sebagai hopes dan fears. Behavioral. Komponen behavioral dibagi menjadi dua, yaitu: exploration dan komitmen.

\section{KESIMPULAN}

Konseling berbasis kesehatan mental sangat di butuhkan bagi narapidana di Lapas untuk mengentaskan masalah yang berkaitan baik bagi narapidana yang dalam masa tahanan, terpidana mati maupun yang akan kembali ke kehidupan masyarakat. Dalam pemberian layanan haruslah fokus pada kebutuhan, krisis stabilitas, bukan pada lamanya pemberian layanan dan layanan yang idberikan dapat menggunakan berbagai teknik seperti Art Therapy, serta dalam memberikan pelayanan sebaiknya konselor dapat menerima klien apa adanya, dengan segala yang keunikan yang dimiliki klien.

\section{REFERENCES}

Aba Afari, S., Osei, M., \& Adu-Agyem, J. (2015). Recidivism at the Kumasi Central Prison : A look into Guidance and Counselling Services. Journal of Education and Practice, 6(9), 130-137. Retrieved from https://files.eric.ed.gov/fulltext/EJ1082450.pdf

Ag, M. (2015). PSIKOLOGI AGAMA: Sebuah Model Psikoterapi Islam dalam Mewujudkan Kesehatan Mental. Seminar Nasional Bimbingan Dan Konseling Dan Konsorsium Keilmuan BK Di PTKI Batusangkar, 28 - 29 November 2015, (November), 28-29.

Batang, I. D. I., Akbar, M. R., \& Primatexco, P. T. (2013). Journal of Social and Industrial Psychology ENGAGEMENT EMPLOYEE. Journal of Social and Industrial Psychology, 2(1), 10-18.

Daifotis, K. (2018). Mental Health in U . S . Prisons: How Our System Is Set Up For Failure.

Gussak, D. (2007). The effectiveness of art therapy in reducing depression in prison populations. International Journal of Offender Therapy and Comparative Criminology, 51(4), 444-460. https://doi.org/10.1177/0306624X06294137

Hasan Ramli dan Wiwik Utami, A. (2012). Urgensi Penyusunan Model Bimbingan Kesehatan Mental (Mental Hygiene) Selama Menunggu Eksekusi Mati. De Jure: Jurnal Hukum Dan Syar'iah, 4(1), 34-48.

Hayati, N. U. R. (2015). WANITA KLAS II A SEMARANG ( Prespektif Bimbingan Konseling Keluarga Islami ). 
Indonesia, R. (1995). www.bphn.go.id.

Karnovinanda Rhapsody, T. S. (2014). Prevalensi Depresi pada Narapidana di Lembaga Permasyarakatan Anak. Majalah Kedokteran Sriwijaya, 46(4), 243-249.

Kepemudaan, P. (2013). Bagaimana Hidup Saya Setelah Ini ?, 2(1), 63-74.

Megah Andriany. (2011). Rencana Narapidana Wanita Menghadapi Kebebasan Di Lapas Wanita Kelas Iia Semarang: Konteks Correctional Nursing, 3(Ii), 1-10.

Morgan, R. D., Rozycki, A. T., \& Wilson, S. (2004). Inmate perceptions of mental health services. Professional Psychology: Research and Practice, 35(4), 389-396. https://doi.org/10.1037/0735-7028.35.4.389

Program, C. S. (n.d.). EFFECT OF INDIVIDUAL COUNSELING SERVICES FOR MENTAL HEALTH WOMEN PRISONERS ( Case Non Drugs ) IN KESEHATAN MENTAL WARGA BINAAN WANITA ( Kasus Non Narkoba ) DI LAPAS ANAK PEKANBARU, 1-10.

Psikis, E., Polisi, D. I., \& Padang, R. (2012). Profil kesehatan mental narapidana ditinjau dari emosi psikis di polisi resort padang panjang 1.

Service, P., \& England, P. H. (2019). Mental health in prisons, (June 2017).

Setelah, D. A. N., Di, P., Tahanan, R., \& Kelas, N. (n.d.). 0,05<, 10(Xix), 97-104.

Sosial, M. M. (n.d.). Efektifitas penjara dalam menyelesaikan masalah sosial, 1-20.

Wibawa, A., Utami, Y. S., \& Fatonah, S. (2014). Pola komunikasi konselor dan narapidana, (2).

World Health Organization. (2005). Mental Health and Prisons. World Health Organization, 39(3), 1-7. $\quad$ Retrieved from http://www.who.int/mental_health/policy/mh_in_prison.pdf\%0Awww.who.int/ment al_health/policy/mh_in_prison.pdf

Yusuf, N. M., \& Mundia, L. (2014). The Status of Counseling in Brunei Prisons: Qualitative Exploratory Case Study, (June). https://doi.org/10.5296/jsr.v5i1.5422 